\title{
Quantum Dot Nanometal Surface Energy Transfer Based Biosensing of Sialic Acid Compositions and Linkages in Biological Samples
}

\author{
Raghavendra Kikkeri, ${ }^{\dagger}, \|$ Vered Padler-Karavani, ${ }^{\dagger, \perp}$ Sandra Diaz, ${ }^{\dagger}$ Andrea Verhagen, ${ }^{\dagger}$ Hai Yu, ${ }^{*}$
} Hongzhi Cao, ${ }^{\ddagger}, \nabla$ Martijn A. Langereis, ${ }^{\S, O}$ Raoul J. De Groot, ${ }^{\S}$ Xi Chen, ${ }^{\ddagger}$ and Ajit Varki, ${ }^{* \dagger}$ †Glycobiology Research and Training Center, Departments of Medicine and Cellular and Molecular Medicine, University of
California, San Diego, La Jolla, California, United States
${ }^{\ddagger}$ Department of Chemistry, University of California, Davis, California 95616, United States
${ }^{\S}$ Virology Division, Department of Infectious Diseases and Immunology, Faculty of Veterinary Medicine, Utrecht University, Yalelaan
1, 3584 CL Utrecht, The Netherlands

Supporting Information

ABSTRACT: Current methods for analyzing sialic acid diversity in modifications and linkages require multistep processing, derivatization, and chromatographic analyses. We here report a single-step optical method for identification and quantification of different compositions of sialoglycans on glycoproteins and in serum. This was achieved by measuring and quantifying nanometal surface energy transfer (NSET) signals between quantum dots and gold nanoparticles bound to specific sialic acid binding proteins (SBPs) and sialic acid moieties, respectively. The biosensing process is based on the NSET turn-on by external sialic acid species that compete for binding to the SBPs. Selectivity of the biosensor toward sialoglycans can be designed to detect the total amount, glycosylation linkages ( $\alpha 2-6$ vs $\alpha 2-3$ ), and modifications (9-O-acetyl and $\mathrm{N}$-glycolyl groups) in the samples. This nanobiosensor is a prototype expected to achieve limits of the detection down to the micromolar range for high-throughput quantification and analysis of different compositions of sialoglycans present in biological or biomedical samples.

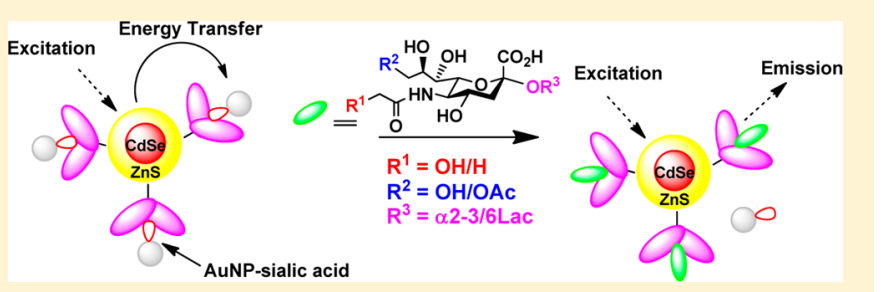

$S^{\mathrm{i}}$ ialic acids (Sias) are a class of monosaccharides typically found at the terminal location of $\mathrm{N}$-glycans, $\mathrm{O}$-glycans, and glycosphingolipids (and occasionally capping side chains of GPI anchors) in animals of the Deuterostome lineage, and in certain bacteria that associate with them. ${ }^{1}$ One of the most striking features of Sias is their structural diversity, with about 50 Sia species known, consisting of $N$-acetylneuraminic acid (Neu5Ac), N-glycolylneuraminic acid (Neu5Gc), keto-deoxynonulosonic acid $(\mathrm{Kdn})$, and their derivatives modified by acetylation, lactylation, methylation, and/or sulfation. ${ }^{2}$ In vertebrates, Sias mediate a wide variety of biological roles, many of which are affected by the modifications and/or linkages of Sias. ${ }^{3}$ For example, the role of CD22 in modulating $\mathrm{B}$ cell receptor (BCR) signaling depends on recognition of $\alpha 2-$ 6 -linked Sias, ${ }^{4}$ and invasion by certain viruses also depends on Sia linkages and/or the presence of Sia-O-acetylation. ${ }^{5}$ Altered sialylation is also a feature of a number of cancers. ${ }^{6}$ Recently we have shown that the nonhuman Sia Neu5Gc is metabolically assimilated from dietary sources onto human cell surfaces and causes antigen-antibody mediated chronic inflammation, which can potentially facilitate disease processes such as tumor progression ${ }^{7}$ and vascular inflammation, ${ }^{8}$ as well as provide epitopes for antibodies as novel cancer biomarkers and immunotherapeutics. ${ }^{9}$ Findings such as these have increased efforts to develop efficient methodologies to quantify sialic acid compositions in biological samples. Most chemosensor methods exploit the interaction between boronic acid and the hydroxyl groups of sialic acids. The drawback of such systems is the nonspecific binding to vicinal cis-diol derivatives. ${ }^{10}$ In contrast, 1,2-diamino-4,5-methylenedioxybenzene (DMB) derivatization followed by reversed-phase high-performance liquid chromatography (RP-HPLC) is most useful for determining labile sialic acids. However, chemical derivatization is necessary to meet detection requirements, and there are multiple steps involved. ${ }^{11}$

Recently, nanotechnology-based biosensors with improved speed, low cost, and direct readout results have been developed as new approaches for the detection of carbohydrates. ${ }^{12}$ We present here the utility of the quantum dot nanometal surface energy transfer (QD-NSET) technique to detect and quantify different compositions of sialoglycans containing diverse sialic acid forms in biological samples. NSET is an efficient quenching technique occurring at distances nearly twice as far as fluorescence resonance energy transfer (FRET). ${ }^{13 a}$ This technique has been extensively used to measure distance for protein interaction on DNA and a $\mathrm{Hg}(\mathrm{II})$ sensor. $^{13}$ In our method, NSET between QDs and gold nanoparticles (AuNPs)

Received: October 9, 2012

Accepted: March 15, 2013

Published: March 15, 2013 
is propagated by specific sialic acid-binding protein-carbohydrate interactions and biosensing is based on the switching-on of $\mathrm{QD}$ fluorescence by adding sialic acids or sialic acidcontaining glycoconjugates that compete for binding to the Siabinding protein (SBP) and therefore remove the quencher AuNP (Figure 1i). To profile sialic acid compositions in

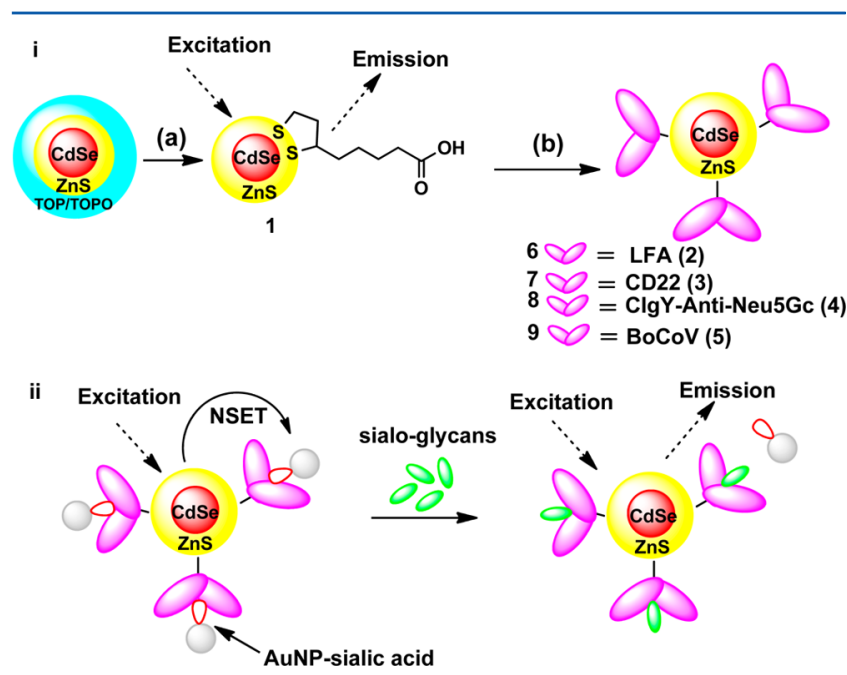

Figure 1. (i) Synthesis of sialic acid binding protein conjugated quantum dots 6-9: (a) DL-thioctic acid $/ \mathrm{NaBH}_{4} / \mathrm{EtOH}$; (b) EDC/ $\mathrm{NHS} / \mathrm{H}_{2} \mathrm{O} /$ sialic acid binding proteins (LFA, CD22, CIgY-AntiNeu5Gc, BoCoV). (ii) Schematic illustration of the NSET-based sialic acid biosensor principles: QDs (6-9) were treated with different AuNPs (13-15) carrying sialic acid residues $(10-12)$ to generate NSET-based photoluminescence quenching of QDs 6-9. Finally, the NSET was disturbed by adding external sialoglycans having strong affinity to SBP (2-5).

biological samples, four SBPs with distinct binding specificity to sialic acid species were immobilized on QDs and reacted with PEGylated gold nanoparticles carrying Neu5Ac/Neu5Gc sugar moieties with or without 9-O-acetyl modifications. ${ }^{9,14}$ Limax flavus agglutinin (LFA), CD22 (Siglec-2), chicken-IgY antiNeu5Gc (CIgY-Anti-Neu5Gc), and bovine coronavirus $\mathrm{HE}^{0}$ (BoCoV) were selected as SBPs (Figure 1; SBP 2, 3, 4, and 5, respectively, yielding QD6, QD7, QD8, and QD9). While LFA is a lectin that binds to all common sialic acids, ${ }^{15}$ human CD22$F_{c}$ is specific to Neu5Ac/Neu5Gc $22-6$-linked sialic acids, ${ }^{16}$ BoCoV is specific to $9-\mathrm{O}$-acetylated sialic acids, ${ }^{17}$ and chicken anti-Neu5Gc-IgY is specific to the nonhuman sialic acid Neu5Gc. ${ }^{18}$

Our results indicate that the QDs-based biosensor requires only a small amount of biomaterials (micromolar range) and provides high selectivity and sensitivity for different composition of sialoglycans, rendering this method attractive.

\section{RESULTS AND DISCUSSION}

Synthesis of Sialic Acid Functionalized Nanoparticles. Cadmium selenide/zinc sulfide (CdSe/ZnS) cores with SBPs were prepared starting from ligand exchange with thioctic acid and tri- $n$-octyl phosphine/tri- $n$-octyl phosphine oxide (TOP/ TOPO)-capped QDs to afford QD-COOH (1). ${ }^{19}$ The terminal carboxylic acid of $\mathbf{1}$ was further reacted with 1-ethyl3-(3-dimethylaminopropyl) carbodiimide and $\mathrm{N}$-hydroxysuccinimide (NHS), before conjugating with LFA, CD22, CIgYAnti-Neu5Gc, and BoCoV (2-5) to yield QDs 6-9, respectively (Figure 1). The conjugated QDs were purified by filtering with a Microcon centrifugal filter device with a cutoff range of $30 \mathrm{kDa}$. The concentration of protein on $\mathrm{CdSe} / \mathrm{ZnS}$ was determined by the BCA assay using a microtiter plate. QDs 6-9 showed 6-7 protein molecules per quantum dot. The gold nanoparticles were obtained by adding a methanol solution of $\mathrm{SH}-\mathrm{PEG}_{2000}-\mathrm{COOH}$ to an aqueous solution of tetrachloroauric acid $\left(\mathrm{HAuCl}_{4}\right)$ (Figure 2). By reduction of the resulting

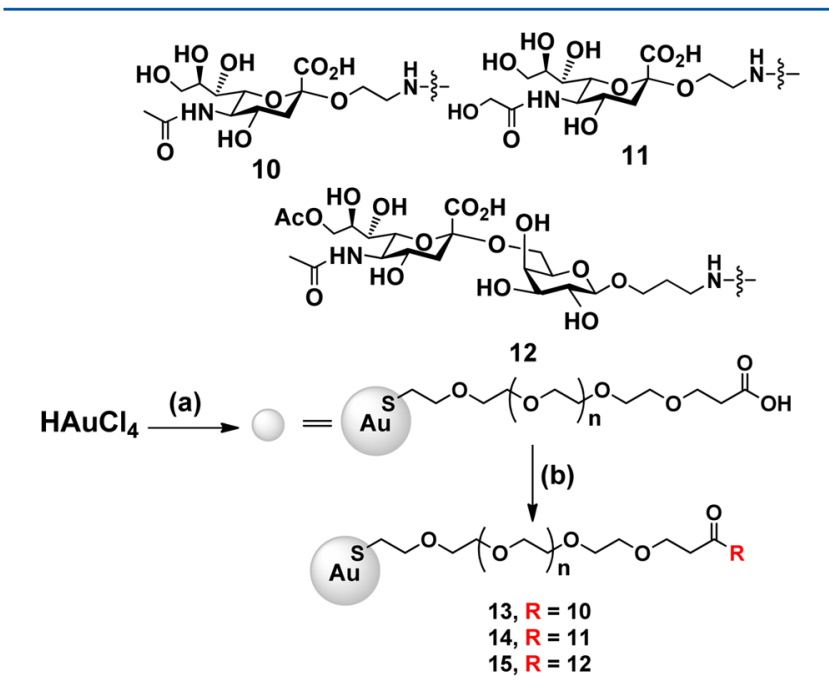

Figure 2. Synthesis of gold nanoparticles 13-15: (a) sodium borohydride/SH-PEG-COOH; (b) Comp 10-12/WSC/NHS.

mixture with $\mathrm{NaBH}_{4}$, a yellow to dark brown suspension was immediately formed. The suspension was shaken for about $2 \mathrm{~h}$, and the solvent was then removed. The nanoparticles were purified by centrifugal filtering and characterized by ${ }^{1} \mathrm{H}$ and ${ }^{13} \mathrm{C}$ NMR and UV-vis spectroscopy. ${ }^{19 \mathrm{~d}}$ The terminal carboxylic acid was further reacted with sialic acid species 10-12 (Figure 2) to yield nanoparticles AuNPs 13-15, respectively. The concentration of sialic acids on AuNPs was determined by acid hydrolysis followed by the DMB-HPLC method, indicating that there were 15-18 sialic acid moieties per AuNP.

After synthesizing QDs and AuNPs, the fluorescence quenching efficiency can be quantified by the Stern-Volmer equation.

$$
F_{0} / F=1+K_{\mathrm{SV}}[\mathrm{AuNP}]
$$

$F_{0}$ and $F$ denote the steady-state fluorescence intensities in the absence and presence of the quencher AuNPs, respectively. A plot of $F_{0} / F$ versus [AuNPs] produced a straight line, as shown in Figure 3, the slope of which gave the Stern-Volmer quenching constant. The experimental values of $K_{\mathrm{SV}}$ of QDs 69 with respect to AuNPs 13-15 are given in the Supporting Information, Tables S1 and S2.

Although the quenching efficiency is quite high, the lack of localized surface plasma resonance (LSPR) of AuNPs 13-15 in the UV-vis absorption spectra suggests the absence of a FRET mechanism (Supporting Information, Figure S3). Instead of FRET, nanometal surface energy transfer (NSET) has been highly successful in describing the fluorescence quenching by small gold nanoparticles. ${ }^{13}$ Recent studies show that NSET does not require a resonance interaction between the donoracceptor probes. According to the Persson and Lang theory, AuNPs ${ }^{17 a}$ with a limited size and surface will accept only a limited amount of energy by the formation of electron-hole pairs near the surface. 
(a)
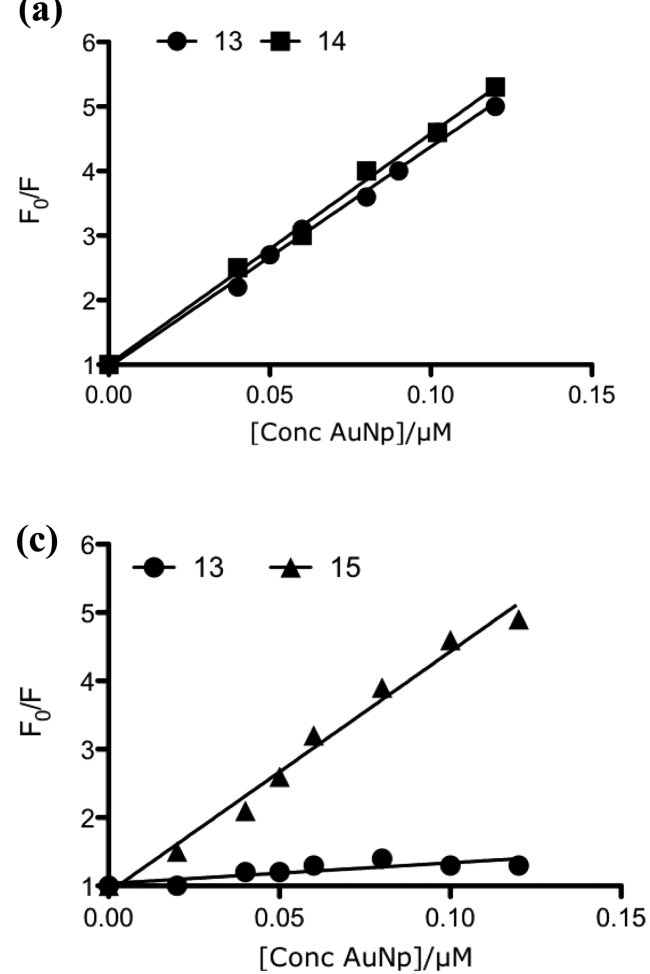

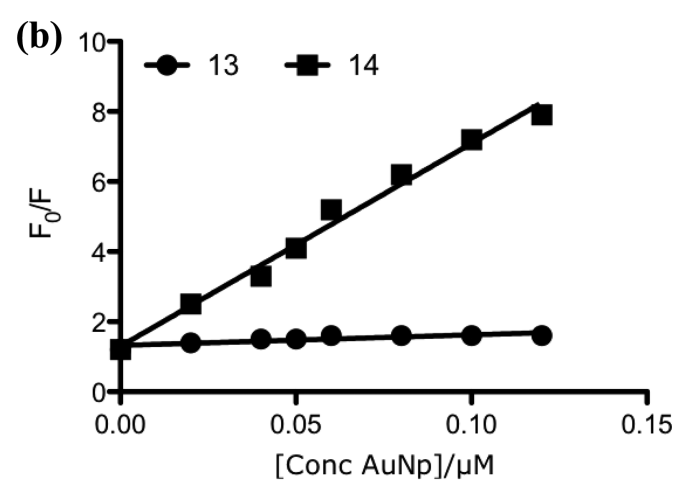

Figure 3. Stern-Volmer plot of $F_{0} / F$ vs $[$ AuNPs]: $(\mathrm{A})[\mathrm{QD}-6]=6 \mathrm{nM},[\mathrm{Au}-13 / 14]=0-150 \mathrm{nM}$ in PBS solution, $\mathrm{pH}=7.4$, incubation time $=1$ $\min ;(B)[Q D-8]=6 \mathrm{nM},[\mathrm{Au}-13 / 14]=0-200 \mathrm{nM}$ in PBS solution, $\mathrm{pH}=7.4$, incubation time $=1 \mathrm{~min}$; $(\mathrm{C})[\mathrm{QD}-9]=6 \mathrm{nM},[\mathrm{Au}-13 / 15]=0-150$ $\mathrm{nM}$ in PBS solution, $\mathrm{pH}=7.4$, incubation time $=1 \mathrm{~min}$.

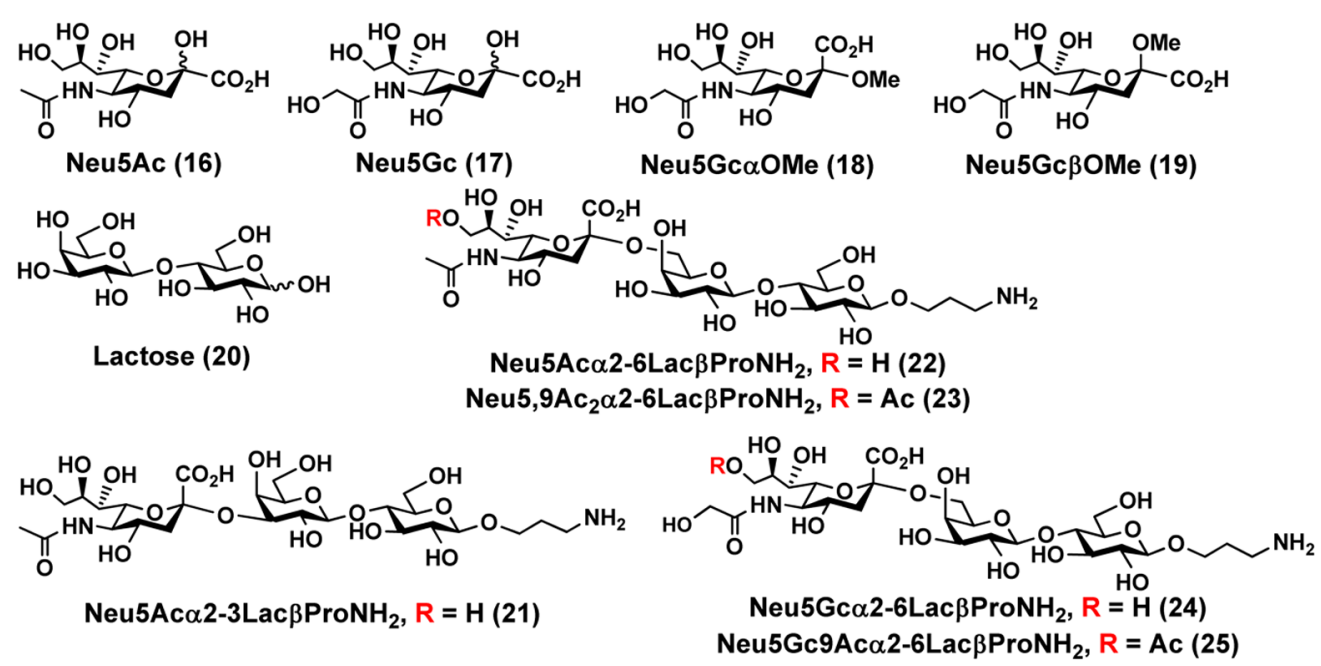

Figure 4. Chemical structures of sialic acid residues used for biosensing process (16-25).

To validate the mechanism of energy transfer from the QDs to the gold nanoparticles, we have examined the separation distance $\left(d_{0}\right)$ at which the energy transfer efficiency is $50 \%$. For the NSET mechanism, $d_{0}$ can be quantified by eq 2 .

$$
d_{0(\mathrm{NSET})}=\left\{\frac{0.225 \Phi_{\mathrm{QD}}}{\omega_{\mathrm{QD}}{ }^{2} \omega_{\mathrm{F}} k_{\mathrm{F}}} c^{3}\right\}^{1 / 4}
$$

$\Phi_{\mathrm{QD}}$ denotes the quantum yield of the QDs 6-9 in the absence of acceptor, $\omega_{\mathrm{QD}}{ }^{2}$ and $c$ are the angular frequency of the donor emission and velocity of light, and $\omega_{\mathrm{F}}=1.2 \times 10^{8} \mathrm{~cm}^{-1}$ and $k_{\mathrm{F}}$ $=8.4 \times 10^{15} \mathrm{rad} / \mathrm{s}$ are the bulk gold angular frequency and Fermi vector, respectively. The $d_{0}$ value in the NSET was calculated to be $6.33 \pm 0.3 \mathrm{~nm}$ from eq 2 for QD- 6 and AuNP13, and this value is better fit to the NSET model of quenching compared to FRET. ${ }^{13}$ This is due to the lack of a pronounced LSPR dipole absorption necessary for FRET.

Furthermore, the quenching constant derived for QDs 6 and 7 was almost the same as the quenching constant with AuNPs 13 and 14 quenchers. QDs 8 and 9 showed preferential quenching with particles 14 and 15, respectively, likely related to preferential binding with the nonhuman sialic acid Neu5Gc and 9-OAc-sialic acid, respectively (Supporting Information, Table S2). On the basis of these results, we constituted four donor/acceptor (NSET-1 (6/13); NSET-2 (7/13); NSET-3 (8/14), and NSET-4 (9/15) models at an optimal concen- 
Table 1. Analytical Parameters (Low Detection Limit, DL; Detection Range, DR) Related to Determination of Different Sialic Acid Species with NSET Mixtures ${ }^{a}$

\begin{tabular}{|c|c|c|c|c|}
\hline sialic acid samples & NSET $-1 \mathrm{DL}$ and (DR) in $\mathrm{nM}$ & NSET-2 DL and (DR) in $n M$ & NSET-3 DL and (DR) in $n M$ & NSET-4 DL and (DR) in $n M$ \\
\hline 16 & $105 \pm 4(100-600)$ & N.M. & N.M. & N.M. \\
\hline 17 & $156 \pm 5(150-780)$ & N.M. & N.M. & N.M. \\
\hline 18 & $28 \pm 1(30-400)$ & N.M. & N.M. & N.M. \\
\hline 19 & 310 & N.M. & N.M. & N.M. \\
\hline 20 & N.M. & N.M. & N.M. & N.M. \\
\hline 21 & $0.5 \pm 0.3(1-285)$ & & N.M. & N.M. \\
\hline 22 & $0.5 \pm 0.2(1-285)$ & $0.2 \pm 0.1(1-175)$ & & \\
\hline 23 & N.M. & N.M. & N.M. & $1.2 \pm 0.5(2-175)$ \\
\hline 24 & $0.5 \pm 0.2(1-290)$ & $0.3 \pm 0.2(1-175)$ & $0.2 \pm 0.2(1-140)$ & \\
\hline 25 & N.M. & N.M. & $0.4 \pm 0.2(1-140)$ & $1.2 \pm 0.5(2-175)$ \\
\hline
\end{tabular}

(a)

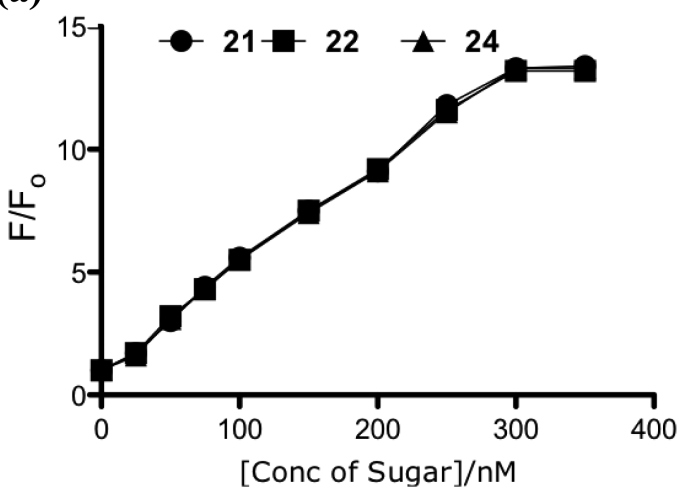

(c)

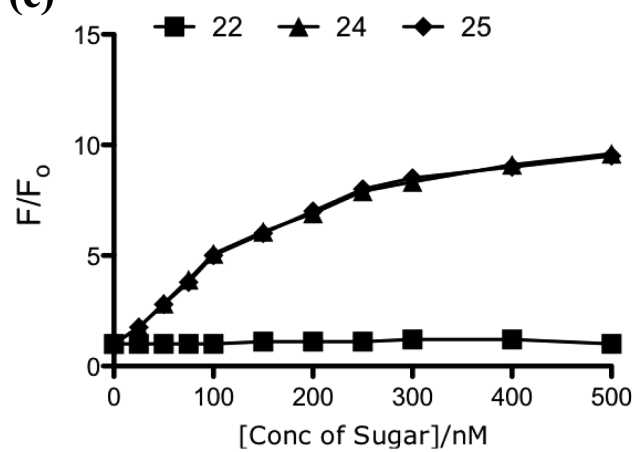

(b)

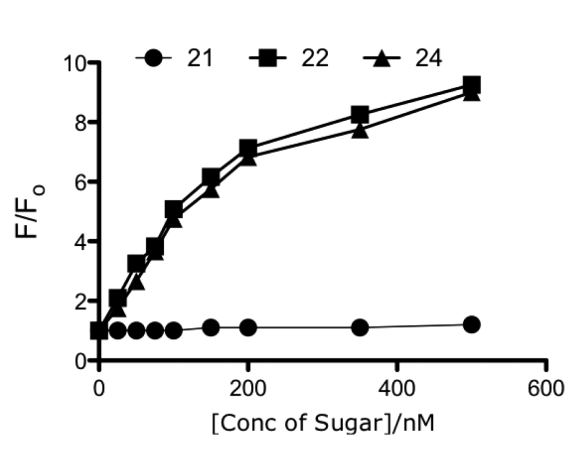

(d)

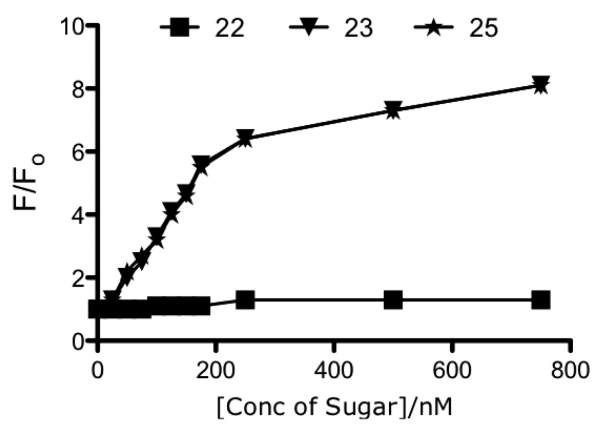

Figure 5. Sialic acid biosensor using different donor/acceptor compositions. (a) Fluorescence increase of NSET-1 (QD-6/Au-13) in presence of increasing concentrations of sialic acid residues $(\mathbf{2 1 - 2 5})[\mathrm{QD}-6]=6 \mathrm{nM},[\mathrm{Au}-13]=110$; total volume $100 \mu \mathrm{L}, \mathrm{PBS} \mathrm{pH}=7.4$; incubation time $=1$ $\mathrm{h}$; RT; $[\mathbf{2 1 / 2 2 / 2 4}]=0-350 \mathrm{nM}$; incubation time $=1 \mathrm{~min} ; \lambda_{\text {exc }}=450 \mathrm{~nm} ; \lambda_{\text {em }}=640 \mathrm{~nm}$. (b) NSET-2 (QD-7/Au-13): [QD-7] $=6 \mathrm{nM}[\mathrm{Au}-13]=$ $130 \mathrm{nM}$; total volume $100 \mu \mathrm{L}, \mathrm{PBS} \mathrm{pH}=7.4$; incubation time $=1 \mathrm{~h} ; \mathrm{RT} ;[21 / 22 / 24]=0-500 \mathrm{nM}$; incubation time $=1 \mathrm{~min} ; \lambda_{\mathrm{exc}}=450 \mathrm{~nm} ; \lambda_{\mathrm{em}}=$ $640 \mathrm{~nm}$. (c) NSET-3 (QD-8/Au-14): [QD-8] = $6 \mathrm{nM}$, [Au-14] = $120 \mathrm{nM}$; total volume $100 \mu \mathrm{L}, \mathrm{PBS} \mathrm{pH}=7.4$; incubation time = $1 \mathrm{~h}$; RT; $[\mathbf{2 2} / \mathbf{2 4} /$ $25]=0-300 \mathrm{nM}$; incubation time $=1 \mathrm{~min} ; \lambda_{\text {exc }}=450 \mathrm{~nm} ; \lambda_{\mathrm{em}}=640 \mathrm{~nm}$. (d) NSET-4 (QD-9/Au-15): [QD-9] $=6 \mathrm{nM},[\mathrm{Au}-15]=120 \mathrm{nM}$; total volume $100 \mu \mathrm{L}$, PBS pH = 7.4; incubation time $=1 \mathrm{~h}$; RT; $[22 / 23 / 25]=0-250 \mathrm{nM}$; incubation time $=1 \min ; \lambda_{\text {exc }}=450 \mathrm{~nm} ; \lambda_{\text {em }}=640 \mathrm{~nm}$. All experimental values are aggregates of three parallel experiments.

tration useful for efficient NSET process and then studied how selective and sensitive these mixtures were as Sia biosensors.

To screen binding of different sialoglycans, four sialic acid monosaccharides (16-19) and five sialoglycans (21-25) were used representing the most common terminal-sialylated structures (Figure 4 and Table 1). Using NSET-1 (6/13) as a donor/acceptor mixture, a uniform increase in the fluorescence upon the addition of 100 and $150 \mathrm{nM}$ of compounds 16 and 17 and saturation in the signal at 600 and $700 \mathrm{nM}$ was observed (Supporting Information, Figure S2). A similar experiment with compound $\mathbf{1 8}$ displayed much more sensitive gain in fluorescence compared to compound 19 , indicating sensitivity of the LFA toward $\alpha$-sialic acid species. On the basis of these results, the detection limit and detection range for free sialic acid were determined (Table 1).

In contrast, increasing concentration of sialylated glycans $\mathbf{2 1}$, $\mathbf{2 2}$, and $\mathbf{2 4}$ resulted in a rapid concentration-dependent increase in fluorescence (Figure 5a). The detection limit for these sugars was in the range of $0.4-0.5 \mathrm{nM}$ (Table 1). Moreover, the LFA binding trend is similar for $\alpha 2-3-$ and $\alpha 2-6$-linked sialoglycans. To test for sialic acid sensitivity of human CD22-Fc, the NSET-2 (7/13) mixture was treated with 1- 
(a)

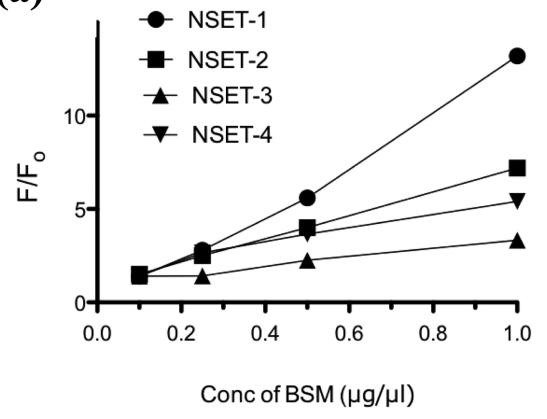

(d)

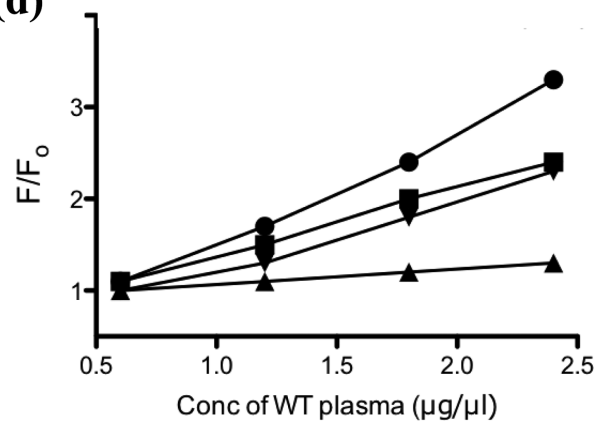

(b)

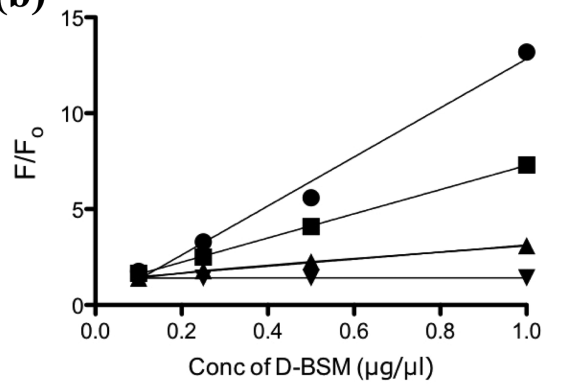

(e)

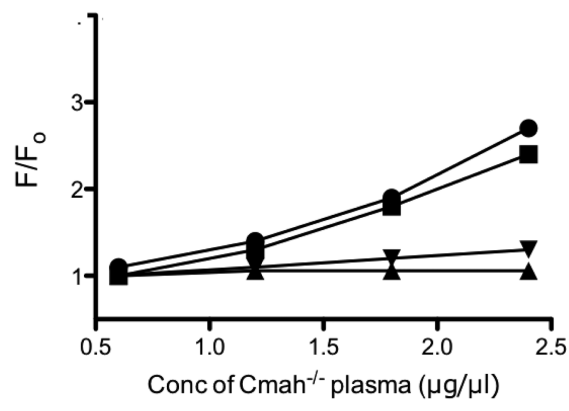

(c)

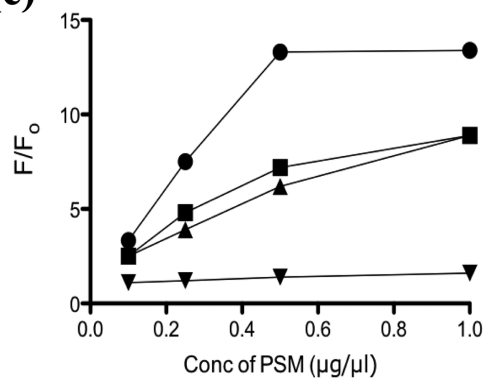

Figure 6. Variation of the fluorescence intensity ratio $F / F_{0}$ as a function of the molar biological samples fractions $(x)$. Solvent: PBS; [NSET-1 to 4] remain the same as in Figure 2. (a) $[\mathrm{BSM}]=0.1-1 \mu \mathrm{g} / \mu \mathrm{L}$; total volume $=100 \mu \mathrm{L}$; incubation time $=1 \mathrm{~min} ; \lambda_{\text {exc }}=450 \mathrm{~nm} ; \lambda_{\mathrm{em}}=640 \mathrm{~nm}$; $(\mathrm{b})[\mathrm{D}$ $\mathrm{BSM}]=0.1-1 \mu \mathrm{g} / \mu \mathrm{L}$; total volume $=100 \mu \mathrm{L}$; incubation time $=1 \mathrm{~min} ; \lambda_{\mathrm{exc}}=450 \mathrm{~nm} ; \lambda_{\mathrm{em}}=640 \mathrm{~nm} ;(\mathrm{c})[\mathrm{PSM}]=0.1-1 \mu \mathrm{g} / \mu \mathrm{L}$; total volume $=$ $100 \mu \mathrm{L}$; incubation time $=1 \mathrm{~min} ; \lambda_{\text {exc }}=450 \mathrm{~nm} ; \lambda_{\text {em }}=640 \mathrm{~nm}$; (d) [WT plasma] $=0.6-2.4 \mu \mathrm{g} / \mu \mathrm{L}$; total volume $=100 \mu \mathrm{L}$; incubation time $=1$ $\min ; \lambda_{\text {exc }}=450 \mathrm{~nm} ; \lambda_{\text {em }} 640 \mathrm{~nm}$; (e) $\left[\mathrm{Cmah}^{-/-}\right.$plasma $]=0.6-2.4 \mu \mathrm{g} / \mu \mathrm{L} ;$ total volume $=100 \mu \mathrm{L} ;$ incubation time $=1 \mathrm{~min} ; \lambda_{\text {exc }}=450 \mathrm{~nm} ; \lambda_{\text {em }}=640$ $\mathrm{nm}$. All experimental values are aggregates of three parallel experiments.

$300 \mathrm{nM}$ of 21,22 , and 24 , respectively. By plotting the relative fluorescence increase $\left(F / F_{0}\right)$ versus Sia concentration, binding isotherms were obtained (Figure $5 \mathrm{~b}$ ). As expected, 21 did not show any binding. Similar experiments with NSET-3 (8/14) and NSET-4 (9/15) mixtures resulted in noticeable preferential fluorescence gain with Neu5Gc and 9-OAc-sialic acid specific glycans, respectively (Figure 5, parts $\mathrm{c}$ and $\mathrm{d}$ ). The detection limits for compounds 22,24 , and 25 were calculated based on these results and found to be 0.2 and $1.2 \mathrm{nM}$, respectively. We observed two phases of fluorescence gain: a uniform rapid fluorescence gain, which can be interpreted as a simultaneous displacement of weakly bound glyco-AuNPs from immobilized SBP and a high affinity of the sugars for protein, and a slow gain that might be due to bulkiness of gold nanoparticles not allowing high-affinity sugars to displace effectively. Finally, the detection limit measured by this method was compared to other QD-based sugar biosensors (Supporting Information, Table S7). ${ }^{20}$

The selectivity of donor/acceptor mixture toward sialoglycans was further demonstrated using a series of solutions (water and PBS solution) containing one or a mixture of representative metals $\left(\mathrm{Na}^{+}, \mathrm{K}^{+}, \mathrm{Ca}^{2+}, \mathrm{Zn}^{2+}\right.$, and $\left.\mathrm{Cu}^{2+}\right)$ or amino acids (leucine, alanine, glycine, aspartic acid, and glutamic acid) or sugars (glucose, maltose, lactose, and dextran) none of which gave fluorescence (Supporting Information, Table S4). The QD/Au mixture can be used to detect the amount of sialic acids with 90-98\% accuracy, even after several weeks at $-20{ }^{\circ} \mathrm{C}$, showing the stability of the method. The change in accuracy is due to the aggregation of nanoparticles and decrease in the quantum yield of the QDs.
After establishing that the QD-NSET method can quantify synthetic sialoglycan sensitively, we evaluated the applicability of these nanobiosensors to determine the various compositions of sialic acids in biological samples. We used model glycoproteins and different sera with a wide range of sialic acid compositions. An array of four NSET mixtures carrying specific SBP-sialic acid moieties was exposed to PBS solution containing $0.1,0.25,0.5$, and $1.0 \mu \mathrm{g} / \mu \mathrm{L}$ solution of bovine submaxillary mucin (BSM), de-O-acetylated (D-BSM) and porcine submaxillary mucin (PSM) solutions, respectively, and change in fluorescence intensity was recorded after $1 \mathrm{~min}$ of exposure time. The quantification of sialic acid content in biosamples was derived from the standard curve obtained with the NSET mixture and standard sialoglycan compounds 21-25 (Figure 6 and Supporting Information Table S5). Upon addition of BSM to NSET-1 mixture in PBS, a concentrationdependent spontaneous fluorescence gain is observed, indicating that sialic acid moieties on BSM successfully displace AuNPs 13, and the resultant fluorescence gain indicates the total sialic acid concentration in a given sample. Alternatively, when BSM was added to NSET-2 mixture in PBS, an enhancement of the fluorescence was relatively lower than that of NSET-1 mixture, indicating the amount of $\alpha 2-6$ sialoglycans is around $58-76 \%$ of the total sialic acid concentration. A similar experiment with NSET-3 resulted in a smaller fluorescence increase indicating the amount of Neu5Gc is around $21-41 \%$ of the total sialic acid. In contrast, NSET-4 showed a large gain in the fluorescence, because 62$71 \%$ of the sialic acids in BSM are 9-O-acetylated (Figure 6a). Finally, the Sia concentration measured by this method was 
compared to the data obtained by the standard DMB-HPLC method (Table 2 and Supporting Information Table S6).

Table 2. Comparison of Results with QD-NSET and DMBHPLC Analysis: Protein Concentration of Mouse Serum = $70 \mu \mathrm{g} / \mu \mathrm{L}_{\text {Protein }}{ }^{a}$

\begin{tabular}{|c|c|c|c|c|}
\hline sample & method & $\begin{array}{c}\text { total Sia } \\
(\mathrm{pmol} / \mu \mathrm{g})\end{array}$ & $\begin{array}{l}\text { Neu5Gc (\% of } \\
\text { total sialic } \\
\text { acid) }\end{array}$ & $\begin{array}{c}\text { 9-OAc-Sia (\% } \\
\text { of total sialic } \\
\text { acid) }\end{array}$ \\
\hline \multirow{2}{*}{$\begin{array}{l}\text { bovine } \\
\text { submaxillary } \\
\text { mucin (BSM) }\end{array}$} & DMB & 300 & 22 & 55 \\
\hline & $\begin{array}{l}\text { QD- } \\
\text { NSET }\end{array}$ & $309 \pm 11$ & $21-41$ & $62-71$ \\
\hline \multirow{2}{*}{$\begin{array}{l}\text { porcine } \\
\text { submaxillary } \\
\text { mucin (PSM) }\end{array}$} & DMB & 603 & 84 & 10 \\
\hline & $\begin{array}{l}\text { QD- } \\
\text { NSET }\end{array}$ & $\begin{array}{l}294 \pm 7 \\
\quad(0.5 \mu \mathrm{g})\end{array}$ & $70-79$ & $7-21$ \\
\hline \multirow{2}{*}{$\begin{array}{l}\text { WT mouse } \\
\text { blood plasma }\end{array}$} & $\mathrm{DMB}$ & 12.2 & 70 & 4 \\
\hline & $\begin{array}{l}\text { QD- } \\
\text { NSET }\end{array}$ & $12 \pm 4$ & $50-60$ & $13-31$ \\
\hline \multirow{2}{*}{$\begin{array}{c}\mathrm{Cmah}^{-/-} \text {mouse } \\
\text { blood plasma }\end{array}$} & $\mathrm{DMB}$ & 9.7 & 1 & 29 \\
\hline & $\begin{array}{l}\text { QD- } \\
\text { NSET }\end{array}$ & $8 \pm 3$ & $1-10$ & $31-53$ \\
\hline
\end{tabular}

${ }^{a}$ All experimental values are aggregates of three parallel experiments.

The fluorescence gain in NSET-1, -2, and -4 with D-BSM was almost identical to BSM. However, NSET-3 showed very weak fluorescence since base treatment eliminates most 9-OAc groups, leaving a free $\mathrm{OH}$ form (Figure 6b). In contrast, in PSM, the fluorescence was saturated after $0.5 \mu \mathrm{g} / \mu \mathrm{L}$ sample. This shows that PSM has more sialoglycans compare to BSM and D-BSM samples, and NSET-4 showed significant fluorescence gain indicating a smaller percent of the Sias are 9-O-acetylated (Figure 6c).

After successfully studying the sialic acid compositions in model glycoproteins, we performed the same experiments with blood plasma samples from wild-type and $\mathrm{Cmah}^{-/-}$mice. Figure 6, parts $\mathrm{d}$ and e, displays NSET mixture behavior at different concentrations of biological samples. As expected, wild-type plasma contains $67-74 \% \alpha 2-6$ sialoglycans, $13-31 \%$ 9-O-acetylation, and 50-60\% Neu5Gc, respectively (Supporting Information, Table S6). Finally, QD-NSET analysis showed that $\mathrm{Cmah}^{-1-}$ plasma sialic acid contains $66-88 \% \quad \alpha 2-6$ sialoglycans, 31-53\% 9-O-acetylated, and 1-10\% Neu5Gc sugars, respectively (Supporting Information, Table S6). Importantly, all these values are in reasonably close agreement with more precise quantitation obtained with the DMB-HPLC method.

\section{CONCLUSIONS}

In conclusion, we have developed a single-step and rapid QDNSET-based methodology for direct detection of different compositions of sialic acids in biological samples. Our methodology is based on sialic acid specific carbohydrateprotein interactions. The sensitivity of the sensor depends on the SBP that is employed. Using LFA, we detected total concentration of sialic acid in a given sample. CD22, CIgYAnti-Neu5Gc, and BoCoV were able to detect different linkages and forms of sialic acids. An array containing all these four SBP NSET mixtures would render high-throughput detection of different forms of sialic acid composition in a single platform.

\section{ASSOCIATED CONTENT}

\section{Supporting Information}

Additional information as noted in text. This material is available free of charge via the Internet at http://pubs.acs.org.

\section{AUTHOR INFORMATION}

\section{Corresponding Author}

*E-mail: alvarki@ucsd.edu.

\section{Present Addresses}

"Department of Chemistry, Indian Institute of Science Education and Research, Pune-411021, India.

${ }^{\perp}$ Department of Cell Research and Immunology, Tel Aviv University, Tel Aviv 69978, Israel.

${ }^{\nabla}$ National Glycoengineering Research Center, Shandong University, Jinan, Shandong 250012, People's Republic of China.

ODepartment of Medical Microbiology, Nijmegen Centre for Molecular Life Sciences and Nijmegen Institute for Infection, Inflammation and Immunity, Radboud University Nijmegen Medical Centre, Nijmegen, Netherlands.

\section{Notes}

The authors declare no competing financial interest.

\section{ACKNOWLEDGMENTS}

This work is supported by NIH Grant GM32373 to A.V., GM076360 to X.C., and ECHO Grants of the Council for Chemical Sciences of The Netherlands Organization for Scientific Research (NWO-CW). This work was also supported by an ISEF postdoctoral fellowship to V.P.-K.

\section{REFERENCES}

(1) Hakomori, S. Cancer Res. 1996, 56, 5309.

(2) (a) Angata, T.; Varki, A. Chem. Rev. 2002, 102, 439-469. (b) Varki, A.; Cummings, R. D.; Esko, J. D.; Freeze, H. H.; Stanley, P.; Bertozzi, C. R.; Hart, G. W.; Etzler. M. E. Essentials of Glycobiology, 2nd ed.; Cold Spring Harbor Press: Cold Spring Harbor, NY, 2009; pp 199-218. (c) Chen, X.; Varki, A. ACS Chem. Biol. 2010, 5, 163.

(3) (a) Schauer, R. Curr. Opin. Struct. Biol. 2009, 19, 507. (b) Varki, A. Trends Mol. Med. 2008, 14, 351.

(4) (a) Powell, L. D.; Varki, A. J. Biol. Chem. 1994, 269, 10628 (b) Brinkman-Van der Linden, E. C. M.; Sjoberg, E. R; Juneja, L. R.; Crocker, P. R.; Varki, N.; Varki, A. J. Biol. Chem. 2000, 275, 8633.

(5) (a) de Groot, R. J. Glycoconjugate J. 2006, 23, 59. (b) Schwegmann-Wessels, C.; Herrler, G. Glycoconjugate J. 2006, 23, 51.

(6) (a) Kim, Y. J.; Varki, A. Glycoconjugate J. 1997, 14, 569-576. (b) Cazet, A.; Julien, S.; Bobowski, M.; Krzewinski-Recchi, M. A.; Harduin-Lepers, A.; Groux-Degroote, S.; Delannoy, P. Carbohydr. Res. 2010, 345, 1377.

(7) (a) Tangvoranuntakul, P.; Gagneux, P.; Diaz, S.; Bardor, M.; Varki, N.; Varki, A.; Muchmore, E. Proc. Natl. Acad. Sci. U.S.A. 2003, 100, 12045-12050. (b) Hedlund, M.; Padler-Karavani, V.; Varki, N. M.; Varki, A. Proc. Natl. Acad. Sci. U.S.A. 2008, 105, 18936. (c) Taylor, R. E.; Gregg, C. J.; Padler-Karavani, V.; Ghaderi, D.; Yu, H.; Huang, S.; Sorensen, R. U.; Chen, X.; Inostroza, J.; Nizet, V.; Varki, A. J. Exp. Med. 2010, 207, 1637-1646. (d) Varki, A. Glycoconjugate. J. 2009, 26, 231.

(8) Pham, T.; Gregg, C. J.; Karp, F.; Chow, R.; Padlaer-Karavani, V.; Cao, H.; Chen, X.; Witztum, J. L.; Varki, N. M.; Varki, A. Blood 2009, 10,5225 .

(9) Padler-Karavani, V.; Hurtado-Ziola, N.; Pu, M.; Yu, H.; Huang, S.; Muthana, S.; Chokhawala, H. A.; Cao, H.; Secrest, P.; FriedmannMorvinski, D.; Singer, O.; Ghaderi, D.; Verma, I. M.; Liu, Y.-T.; Messer, K.; Chen, X.; Varki, A.; Schwab, R. Cancer Res. 2011, 71, $3352-3363$. 
(10) (a) Levonis, S. M.; Kiefel, M. J.; Houston, T. A. Chem. Commun. 2009, 2278. (b) James, T. D.; Sandanayake, K. R. A. S.; Shinkai, S. Nature 1995, 374, 345. (c) Badugu, R.; Lakowicz, J. R.; Geddes, C. D. Talanta 2005, 65, 762 .

(11) Hara, S.; Takemori, Y.; Yamaguchi, M.; Nakamura, M.; Ohkura, Y. Anal. Biochem. 1987, 164, 138.

(12) (a) Ianniello, R. M.; Yacynyeh, A. M. Anal. Chem. 1981, 53, 2090. (b) Cao, L.; Ye, J.; Tong, L.; Tang, B. Chem.-Eur. J. 2008, 31, 9633. (c) Tang, B.; Cao, L.; Xu, K.; Zhuo, L.; Ge, J.; Li, Q.; Yu, L. Chem.-Eur. J. 2008, 14, 3637-3644. (d) Li, X.; Zhou, Y.; Zheng, Z.; Yue, X.; Dai, Z.; Liu, S.; Tang, Z. Langmuir 2009, 25, 6580. (e) Aslan, K.; Zhang, J.; Lakowicz, J. R.; Geddes, C. D. J. Fluoresc. 2004, 14, 391. (f) Aslan, K.; Lakowicz, J. R.; Geddes, C. D. Anal. Biochem. 2004, 330, 145. (g) Rossi, L. M.; Quach, A. D.; Rosenzweig, Z. Anal. Bioanal. Chem. 2004, 380, 606. (h) Zhang, Y.; Mali, B. L.; Aitken, C.; Geddes, C. D. J. Fluoresc. 2013, 23, 187. (i) Dragen, A. I.; Albrecht, M. T.; Pavlovic, R.; Keane-Myers, A. M.; Geddes, C. D. Anal. Biochem. 2012, 425, 54. (j) Thanh, N. T.; Rosenzweig, Z. Anal. Chem. 2002, 74, 1624. (k) El-Ansary, A.; Faddah, L. M. Nanotechnol., Sci. Appl. 2010, 3, 65.

(13) (a) Persson, B.; Long, N. Phys. Rev. B 1982, 26, 5409. (b) Li, M.; Wang, Q.; Shi, X.; Hornak, L.; Wu, N. Anal. Chem. 2011, 83, 7061. (c) Li, M.; Cushing, S. K.; Wang, Q.; Shi, Z.; Hornak, L. A.; Hong, Z.; Wu, N. J. Phys. Chem. Lett. 2011, 2, 2125. (d) Singh, M. P.; Strouse, G. F. J. Am. Chem. Soc. 2010, 132, 9383. (e) Jennings, T. L.; Schlatterer, J. C.; Singh, M. P.; Greenbaum, N. L.; Strouse, G. F. Nano Lett. 2006, 6, 1318.

(14) (a) Yu, H.; Chokhawala, H.; Karpel, R.; Yu, H.; Wu, B.; Zhang, J.; Zhang, Y.; Jia, Q.; Chen, X. J. Am. Chem. Soc. 2005, 127, 17618.

(b) Yu, H.; Huang, S.; Chokhawala, H.; Sun, M.; Zhang, H.; Chen, X. Angew. Chem., Int. Ed. 2006, 12, 3938.

(15) Miller, R. L.; Cannon, J. D., Jr. Prog. Clin. Biol. Res. 1984, 157, 31.

(16) (a) Chen, W. C.; Completo, G. C.; Sigal, D. S.; Crocker, P. R.; Saven, A.; Paulson, J. C. Blood 2010, 115, 4778. (b) Razi, N.; Varki, A. Proc. Natl. Acad. Sci. U.S.A. 1998, 95, 7469.

(17) (a) Zeng, Q.; Langeris, M. A.; vanVliet, A. L.; Huizinga, E. G.; de Groot, R. J. Proc. Natl. Acad. Sci. U.S.A. 2008, 105 (26), 9065. (b) Padler-Karavani, V.; Song, X.; Yu, H.; Hurtado-Ziola, N.; Huang, S.; Muthana, S.; Chokhawala, H. A.; Cheng, J.; Verhagen, A.; Langereis, M. A.; Kleene, R.; Schachner, M.; de Groot, R. J.; Lasanajak, Y.; Matsuda, H.; Schwab, R.; Chen, X.; Smith, D. F.; Cummings, R. D.; Varki, A. J. Biol. Chem. 2012, 287, 22593-22608.

(18) Diaz, S. L.; Padler-Karavani, V.; Ghaderi, D.; Hurtado-Ziola, N.; Yu, H.; Brinkman-Van der Linden, E. C. M.; Varki, A.; Varki, N. PLoS ONE 2009, 4, 4241. (b) Padler-Karavani, V.; Hurtado-Ziola, N.; Pu, M.; Yu, H.; Huang, S.; Muthana, S.; Chokhawala, H. A.; Cao, H.; Secrest, P.; Friedmann-Morvinski, D.; Singer, O.; Ghaderi, D.; Verma, I. M.; Liu, Y. T.; Messer, K.; Chen, X.; Varki, A.; Schwab, R. J. Biol. Chem. 2011, 71, 3352.

(19) (a) Kikker, R.; Lepenies, B.; Adibekian, A.; Laurino, P.; Seeberger, P. H. J. Am. Chem. Soc. 2009, 18, 2110. (b) Patel, P. C.; Giljohann, D. A.; Daniel, W. L.; Zheng, D.; Prigodich, A. E.; Mirkin, C. A. Bioconjugate Chem. 2010, 21, 2250. (c) Thaxton, C. S.; Hill, H. D.; Georganopoulou, D. G.; Stoeva, S. I.; Mirkin, C. A. Anal. Chem. 2005, 77, 8174. (d) Orbach, M.; Lahav, M.; Milko, P.; Wolf, S. G.; Van der Boom, M. E. Angew. Chem., Int. Ed. 2012, 51, 7142. (e) Wang, H.; Chen, L. O.; Shen, X.; Zhu, L.; He, J.; Chen, H. Angew. Chem., Int. Ed. 2012, 51, 8021.

(20) (a) Tang, B.; Cao, L.; Xu, K.; Zhuo, L.; Ge, J.; Li, Q.; Yu, L. Chem.-Eur. J. 2008, 14, 3637. (b) Dai, Z.; Kawde, A.-N.; Xiang, Y.; La Belle, J. T.; Gerlach, J.; Bhavanandan, V. P.; Joshi, L.; Wang, J. J. Am. Chem. Soc. 2006, 128, 10018. 